\title{
Siloxane Oligomer with Random Structure for Use in Photosensitive White Decorative Coatings
}

\author{
Mitsuhito Suwa*, Toru Okazawa, and Hideyuki Kobayashi \\ Electronic and Imaging Materials Research Laboratories, Toray Industries, Inc., \\ Sonoyama 3-chome, Otsu, Shiga 520-0842, Japan \\ *mitsuhito.suwa.e3@mail.toray
}

\begin{abstract}
A siloxane oligomer (Si-OLIGO-1) was produced by introduction of a bifunctional alkoxysilane into a silsesquioxane composed of a trifunctional alkoxysilane. The oligomer, which can form a thick film, was synthesized by a sol-gel method. This organic/inorganic hybrid material had good transparency and heat resistance. Infrared absorption spectroscopic analysis indicated that Si-OLIGO-1 had a random structure with many acidic silanol groups capable of alkaline development. A novel negative photosensitive white decorative coating that consisted of Si-OLIGO-1 as the base resin and $40 \mathrm{wt} \% \mathrm{TiO}_{2}$ (particle size $250 \mathrm{~nm}$ ) as a white pigment was produced. The coating enabled facile complex decoration. A white cured film of thickness $10 \mu \mathrm{m}$ had the brightness $\left(L^{*}\right)$ and color $\left(a^{*}, b^{*}\right)$ required for the white frame of a display product. Although the coating did not transmit straight light of wavelength $300-700 \mathrm{~nm}$, it gave a good patterning performance (resolution and pattern shape) on irradiation with ultraviolet light at a dose of $200-250 \mathrm{~mJ} / \mathrm{cm}^{2}$. This is because it transmitted both g-line and h-line scattered light.
\end{abstract}

Keywords: Photosensitive, white decorative, $\mathrm{TiO}_{2}$, siloxane oligomer, random

\section{Introduction}

In recent years, many optical materials have been developed for use in devices such as smartphones, tablets, and touch screens. Black or white decorative materials, which contain carbon black or $\mathrm{TiO}_{2}$, respectively, are applied to glass covers to conceal the wiring pattern on the substrate and for decoration [1-6]. Figure 1 shows an example of white decoration on a smartphone.

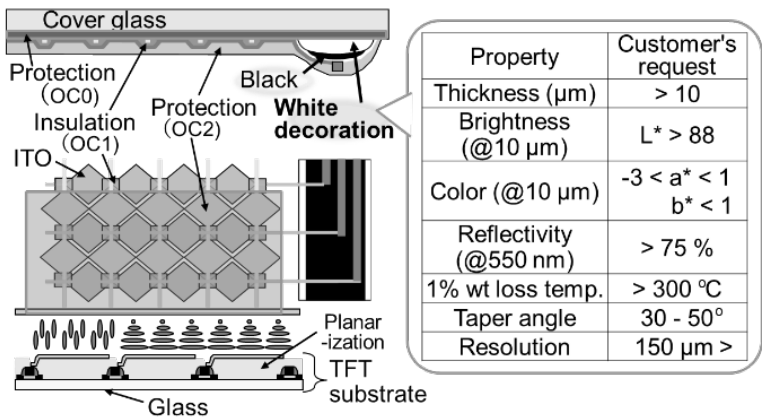

Fig. 1. Example of touch panel with integrated cover glass.
It is generally difficult to endow such decorative materials with photosensitivity because the pigment absorbs not only visible light but also the ultraviolet (UV) light required for photosensitivity. Non-photosensitive materials are usually used for decoration and these cannot form fine patterns for screen-printed complex decoration [1-4] Photosensitive coatings (PS-coatings) with sufficient heat resistance for post-process curing at $230{ }^{\circ} \mathrm{C}$ are therefore needed. This led to the development of black decorative coatings with larger amounts of black pigment [7-9] in a negative photosensitive black matrix for color filters $[5,6]$. However, organic resins with photopolymerizable groups such as methacrylic/acrylic groups, which are used as negative photosensitive base resins for decoration, cannot be used in white decorative coatings because they turn yellow as a result of oxidative deterioration during heat treatment. Furthermore, black decorative materials develop color by absorption, but white decorative materials develop color by using light reflection, therefore films of 
thickness greater than $10 \mu \mathrm{m}$ are required. This increases the need for base resins with heat resistance.

We focused on the heat-resistant materials silsesquioxanes (SQs), which have organic groups that can be used to modify the properties of siloxane materials. These are organic/inorganic hybrid materials with siloxane bonds $(-\mathrm{Si}-\mathrm{O}-\mathrm{Si}-)$ [10-16]. If this siloxane material is used as a base resin, it is unlikely to suffer oxidative deterioration, therefore it can suppress coloring of white decorative materials during heat treatment. As shown in Fig. 2, SQs consist of trifunctional alkoxysilanes and can have highly regular cage and ladder structures, and random structures [11, 16-20].

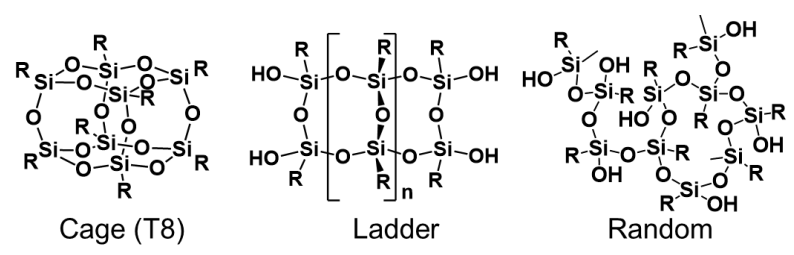

Fig. 2. Higher-order structures of three types of SQ.

The highly regular cage and ladder structures contain few silanol groups, whereas the random structure contains many silanol groups [21-27]. SQ oligomers with phenyl and acrylic organic groups have been synthesized by sol-gel methods $[28,29]$. Negative photosensitive siloxane coatings have been developed by forming a thin cured film of thickness $2 \mu \mathrm{m}$ with oligomers like Si-OLIGO-0, which will be described later, as the base resin. Such coatings are used as insulating materials because the cured product obtained by heat treatment at $230{ }^{\circ} \mathrm{C}$ shows colorless transparency and heat/chemical resistance. We attempted to use the SQ oligomer of Si-OLIGO-0 as a base resin for white decorative coatings. However, because the oligomer consists of trifunctional alkoxysilanes, cracks occur when a cured film of thickness greater than 2-5 $\mu \mathrm{m}$ depending on the added amount of $\mathrm{TiO}_{2}$ is formed as a result of the increased stress associated with a high crosslinking density. Use of this oligomer in practical applications is therefore difficult. The crosslinking density could be decreased by using a siloxane oligomer with a random structure, which could be obtained by introduction of a bifunctional alkoxysilane. This oligomer has decreased stress, which prevents crack formation. It also contains a large amount of silanol groups $\left(\mathrm{p} K_{\mathrm{a}}=9.5\right)$ [30], which are as acidic as phenolic hydroxyl groups $\left(\mathrm{p} K_{\mathrm{a}}=10\right)$ [31]. This oligomer can therefore be easily dissolved in a $2.38 \mathrm{wt} \%$ tetramethylammonium hydroxide (TMAH) aqueous solution as a resist developer, regardless of the film thickness.

We therefore decided to work on imparting negative photosensitivity by using a novel siloxane oligomer with a random structure as the resin material, to give a cured product with colorless transparency, heat resistance, and chemical resistance, and $\mathrm{TiO}_{2}$ of average particle size 250 $\mathrm{nm}$, which is generally used as a white pigment.

The purpose of this study was to create a new negative photosensitive white decorative siloxane coating that gives white cured films with appropriate brightness $\left(L^{*}\right)$, color $\left(a^{*}, b^{*}\right)$, reflectance, heat resistance, and chemical resistance. Despite UV absorption by the $\mathrm{TiO}_{2}$ pigment, the coatings give excellent patterning performances, i.e., good resolution and shape on a film of thickness about $10 \mu \mathrm{m}$.

\section{Experimental}

\subsection{Materials}

Commercially available raw materials were used without purification. The raw materials for the siloxane oligomer preparation solutions were phenyltrimethoxysilane 3-(methacryloyloxy)propyltrimethoxysilane (KBM-503), dimethoxydimethylsilane (KBM-22), [3-(trimethoxysilyl)propyl]succinic anhydride (X-12-967C) (Shin-Etsu Chemical Co., Ltd.), phosphoric acid (Tokyo Chemical Industry Co., Ltd.), and propylene glycol monomethyl ether acetate (PGMEA, Kuraray Co., Ltd.) The acrylic polymer, which was a partial adduct of glycidyl methacrylate and a copolymer of methacrylic acid, styrene, and dicyclopentanyl methacrylate, was prepared from a PGMEA solution of SPCR-24X [weight-average molecular weight $\left(M_{\mathrm{w}}\right): 14000$, solid content $=40 \mathrm{wt} \%$, Showa Denko K.K.]. Epoxide-modified isocyanurate diacrylate (ARONIX M-315, Toagosei Co., Ltd.) was used as the acrylic monomer. Bis(2,4,6-trimethylbenzoyl)phenylphosphine oxide (Omnirad 819, IGM Resins B.V.) was used as a photoinitiator. The white pigment was a $\mathrm{TiO}_{2}$ dispersion (S-5052, solid content $=65.3 \mathrm{wt} \%$, Dainichiseika Kogyo Co., Ltd.) It consisted of CR-97 $\left(\mathrm{TiO}_{2}\right.$ of average particle size $250 \mathrm{~nm}$, Ishihara Sangyo Kaisha, Ltd.) dispersed in the manufacturer's undisclosed dispersant in PGMEA at $5.1 \mathrm{wt} \%$ (relative to $\mathrm{TiO}_{2}$ ). A resist stripper, i.e., N-300 [a mixture of monoethanolamine (MEA) 
and diethylene glycol monobutyl ether (DGBE), MEA/DGBE $=30 / 70$ weight ratio, Nagase ChemteX Co.] and an indium tin oxide (ITO) etchant, i.e., oxalic acid solution $(0.05 \mathrm{~mol} / \mathrm{L}$, FUJIFILM Wako Pure Chemical, Co.) were used for chemical resistance.

Two types of siloxane oligomer solution were prepared by the following general procedure. KBM-103 (0.45 mol), KBM-503 (0.3 mol), $\mathrm{X}-12-967 \mathrm{C}(0.05 \mathrm{~mol}), \mathrm{KBM}-22(0.20 \mathrm{~mol})$ as a bifunctional alkoxysilane, and PGMEA (149 g, 75 $\mathrm{wt} \%$ with respect to charged alkoxysilanes) were placed in a $500 \mathrm{~mL}$ three-necked flask. An aqueous solution, which was prepared by dissolving a phosphoric acid catalyst $(0.3 \mathrm{wt} \%$ with respect to the charged alkoxysilanes in the flask) in water ( $2.85 \mathrm{~mol})$, was added over $30 \mathrm{~min}$ under stirring at room temperature. The flask was immersed in an oil bath at $40{ }^{\circ} \mathrm{C}$ and the solution was stirred for 60 min. The temperature of the oil bath was raised to $70{ }^{\circ} \mathrm{C}$ and the solution was stirred for $60 \mathrm{~min}$. The temperature of the oil bath was then set at $110^{\circ} \mathrm{C}$. The internal temperature of the flask reached $100{ }^{\circ} \mathrm{C}$ after $45 \mathrm{~min}$, and the solution was then stirred for approximately $1.5 \mathrm{~h}$ (the internal temperature was $100-110{ }^{\circ} \mathrm{C}$ ). This step was performed to adjust the dissolution rate of the siloxane oligomer in a $2.38 \mathrm{wt} \% \mathrm{TMAH}$ aqueous solution (ELM-D, Mitsubishi Gas Chemical Company, Inc.) of the alkaline resist developer. During this period, the methanol and water by-products were removed by distillation. The catalyst was removed by adding $3 \mathrm{wt} \%$ Amberlyst A21 (Organo Co.), which is an anion-exchange resin, to the obtained solution and stirring the mixture for $12 \mathrm{~h}$ at room temperature. The ion-exchange resin was removed by wire-mesh filtration (100 mesh). The obtained siloxane oligomer solution (approximately 1 g) was transferred to an aluminum cup. The cup was placed on a hot plate at $120{ }^{\circ} \mathrm{C}$, and heated to $250{ }^{\circ} \mathrm{C}$ in air for $30 \mathrm{~min}$. The aluminum cup was then allowed to cool and the concentration of the solution was calculated by assuming that the dehydration condensation reaction was complete and gave a fully cured siloxane (FS). PGMEA was added to give a solution of concentration $50 \mathrm{wt} \%$; this solution was labeled Si-OLIGO-1. For comparison with Si-OLIGO-1, a solution of the SQ oligomer, labeled Si-OLIGO-0, which was developed for negative photosensitive transparent insulation, was prepared by the same method as was used for Si-OLIGO-1 preparation, but KBM-103, KBM-503, and X-12-967C (1 mol total) at molar ratios of 65:30:5 were used. A 50 wt $\%$ Si-OLIGO-0 solution was obtained under the same conditions as those described above, but with PGMEA (161 g; $75 \mathrm{wt} \%$ with respect to charged alkoxysilanes) and water (3.05 mol).

Transparent PS-coatings were prepared by adding ARONIX M-315, Omnirad 819, and PGMEA to resin solutions of the prepared Si-OLIGO-1, or SPCR-24X. Furthermore, white PS-coatings were prepared by adding S-5052 to the transparent PS-coatings; details are shown in Table 1. The coatings were stirred by shaking under yellow light with a rotary shaker to obtain a uniform solution. The solution was filtered through a $0.45 \mu \mathrm{m}$ polypropylene syringe filter to give the PS-coatings. Solutions of Si-OLIGO-1 and Si-OLIGO-0 were also filtered under the same conditions for characterization of the siloxane oligomers.

2.2. Preparation of prebaked film, cured film, heattreated film, and sample for evaluating patterning properties

The PS-coatings were spin-coated on a non-alkaline glass substrate (OA-10G, Nippon Electric Glass Co., Ltd.), ITO, and Cr substrates

Table 1. Compositions of transparent PS-coatings (a) and (b), and white PS-coatings (c)-(f).

\begin{tabular}{cccccccc}
\hline & \multicolumn{7}{c}{ Composition (weight ratio) } \\
\cline { 2 - 8 } PS-coatings & $\begin{array}{c}\text { Siloxane } \\
\text { oligomer }\end{array}$ & $\begin{array}{c}\text { Acrylic } \\
\text { polymer }\end{array}$ & White pigment & Additives & Monomer & $\begin{array}{c}\text { Photo- } \\
\text { initiator }\end{array}$ & Solvent \\
\cline { 2 - 8 } & Si-OLIGO-1 & SPCR-24X & $\begin{array}{c}\text { S-5052 } \\
\left(\mathrm{TiO}_{2}: 250 \mathrm{~nm}\right)\end{array}$ & Dispersant & M-315 & $\begin{array}{c}\text { Omnirad } \\
819\end{array}$ & PGMEA \\
\hline (a) & $40^{\mathrm{a}}$ & - & - & - & 18 & 2 & 60 \\
(b) & - & $40^{\mathrm{a}}$ & - & - & 18 & 2 & 60 \\
\hline (c) & $40^{\mathrm{a}}$ & - & $20^{\mathrm{a}}$ & 1 & 18 & 2 & 80 \\
(d) & - & $40^{\mathrm{a}}$ & $20^{\mathrm{a}}$ & 1 & 18 & 2 & 80 \\
(e) & $40^{\mathrm{a}}$ & - & $40^{\mathrm{a}}$ & 2 & 18 & 2 & 100 \\
(f) & - & $40^{\mathrm{a}}$ & $40^{\mathrm{a}}$ & 2 & 18 & 2 & 100 \\
\hline \multicolumn{7}{c}{${ }^{\mathrm{a}}$ Converted solid content to $100 \mathrm{wt} \%$} \\
\end{tabular}


(GEOMATEC Co., Ltd.) with a spin coater (1H-360S, Mikasa Co., Ltd.) to obtain a post-curing thickness of $10 \mu \mathrm{m}$. The spin-coated substrates were dried at $100 \mathrm{~Pa}$ for $60 \mathrm{~s}$ in a vacuum dryer (Micro Engineering Inc.), and then baked at $100{ }^{\circ} \mathrm{C}$ for $180 \mathrm{~s}$ on a hot plate (HPD-3000BZN, AZ One Co.) to prepare prebaked films of thickness $11.7 \mu \mathrm{m}$. After baking, the film thickness was determined by scanning electron microscopy (SEM; S-4800, Hitachi High-Tech Co.) These prebaked substrates were exposed at $300 \mathrm{~mJ} / \mathrm{cm}^{2}$ (calculated from the i-line value) without a mask on three substrates, or at 100-300 $\mathrm{mJ} / \mathrm{cm}^{2}$ through a mask with a gap of $50 \mathrm{~mm}$ on glass substrates by using an exposure tool (g-, h-, and i-lines, PLA-501F, Canon Inc.) with a high-pressure mercury lamp as a light source. The mask had a one-line and one-space pattern in the range 10-200 $\mu \mathrm{m}$. The exposed substrates were showered with $2.38 \mathrm{wt} \%$ TMAH aqueous solution for $30 \mathrm{~s}$ (shower development) by using automatic developing equipment (AD-2000, Takizawa Sangyo Co., Ltd.) The substrates were then rinsed with water for $30 \mathrm{~s}$ and air dried. The air-dried substrates were post-baked (cured) in an oven (DN43HI, Yamato scientific Co., Ltd.) at $230{ }^{\circ} \mathrm{C}$ for $30 \mathrm{~min}$ in air. Some of the cured glass substrates were heat treated by post-baking in an oven under the above conditions but at $250{ }^{\circ} \mathrm{C}$ for $30 \mathrm{~min}$. The film thicknesses were determined from SEM images. The cured films and samples for patterning property evaluation were prepared from cured substrates, which were obtained from the exposed substrates without or with masks. The filtered solutions of Si-OLOGO-1 and Si-OLIGO-0 were spin-coated on 6-inch silicon wafers under the above conditions to prepare prebaked films of thickness $11.7 \mu \mathrm{m}$.

\subsection{Evaluation}

2.3.1. Gel-permeation chromatography (GPC) and infrared (IR) spectroscopy

The siloxane oligomer solution was diluted with tetrahydrofuran (THF) to give an FS concentration of $0.1 \mathrm{wt} \%$, on the assumption that the hydrolysis/dehydration condensation reaction was complete. The $M_{\mathrm{w}}$ and molecular-weight distribution were determined by GPC with polystyrene as the standard. GPC was performed at $30{ }^{\circ} \mathrm{C}$ and a flow rate of $1.0 \mathrm{~mL} / \mathrm{min}$, with THF as the developing solvent; a chromatographic system (e2695, Waters Co.) equipped with a refractometer detector and two columns (TSKgel G4000HXL,
TSKgel G1000HXL, Tosoh Co., Ltd.) was used. The IR spectra of the prebaked films of Si-OLIGO-1 or Si-OLIGO-0 on silicon wafers were recorded in transmission mode (FT-720, HORIBA, Ltd.) A silicon wafer was used as a blank. The spectra were used to characterize the siloxane oligomers.

\subsubsection{Transparencies of prebaked and cured films}

The straight $\left(8^{\circ}\right)$ and scattered transmittances of the prebaked film $(11.7 \mu \mathrm{m})$ and straight $\left(8^{\circ}\right)$ transmittance of a cured film (thickness $10 \mu \mathrm{m}$ ) on a glass substrate were determined by UV spectroscopy (UV-4100, Hitachi High-Tech Co.).

\subsection{3. $L^{*}, a^{*}, b^{*}$, and reflectivity}

The brightness $\left(L^{*}\right)$, color $\left(a^{*}, b^{*}\right)$, and reflectivity of the cured film (thickness $10 \mu \mathrm{m}$ ) on a glass substrate were determined in specular component inclusion mode by using a split color meter (CM-2600d, Konica Minolta, Inc.); $a^{*}$ is the redness and $b^{*}$ denotes the yellow tint.

\subsubsection{Heat resistance}

The $1 \%, 3 \%$, and $5 \%$ weight-loss temperatures of the cured film (thickness $10 \mu \mathrm{m}$ ) on a glass substrate were determined by using a thermogravimetric analyzer (TGA-50, SHIMADZU Co.)

\subsubsection{Chemical resistance}

The chemical resistances of the cured film (thickness $10 \mu \mathrm{m}$ ) of PS-coating (e) on glass, ITO, and $\mathrm{Cr}$ substrates were determined by immersion in chemicals under various conditions $(2.38 \mathrm{wt} \%$ TMAH aqueous solution at $23{ }^{\circ} \mathrm{C}$ for $3 \mathrm{~min} ; \mathrm{N}-300$ at $45{ }^{\circ} \mathrm{C}$ for $3 \mathrm{~min}$; oxalic acid solution $35^{\circ} \mathrm{C}$ for 3 $\mathrm{min})$. Changes in the film state were evaluated visually.

2.3.6. Thickness, pattern profile, taper angle, and resolution

The prebaked and cured film thicknesses on their respective substrates were determined from SEM images. The cured pattern profiles and resolutions on glass substrates were observed by SEM. The taper angles and resolutions were determined from SEM images. The pattern resolution was defined as the smallest cured pattern size at which the pattern could be developed without a leaving a residue at each exposure. 


\section{Results and discussion}

\subsection{Structure of synthesized Si-OLIGO-1}

Si-OLIGO-0 was synthesized by using a trifunctional alkoxysilane [organic groups: phenyl $(\mathrm{Ph})$, methacryloylpropyl (Mac), and succinic acid propyl (Suc)]; it provides film insulation. Si-OLIGO-1, which can form $10 \mu \mathrm{m}$ thick films suitable for white decorative coatings, was designed and synthesized by introducing a bifunctional alkoxysilane (organic group: dimethyl, Dime) into Si-OLIGO-0. The effects of bifunctional alkoxysilane introduction were examined by comparing them. The structural formulas are shown in Fig. 3.

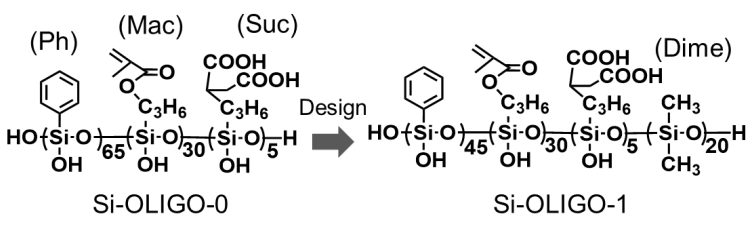

Fig. 3. Structural formulas of synthesized siloxane materials.

GPC was used to determine the $M_{\mathrm{w}} \mathrm{S}$ and polydispersity indexes $\left(M_{\mathrm{w}} / M_{\mathrm{n}} ; \quad M_{\mathrm{n}}=\right.$ number-average molecular weight) of Si-OLIGO-0 and Si-OLIGO-1. The organic group ratios (mol\%) of the charged alkoxysilanes and GPC results are shown in Table 2.

Table 2. Organic group ratios, $M_{\mathrm{w}}$, and $M_{\mathrm{w}} / M_{\mathrm{n}}$ of siloxane materials.

\begin{tabular}{ccccccc}
\hline \multirow{2}{*}{$\begin{array}{l}\text { Siloxane } \\
\text { oligomer }\end{array}$} & \multicolumn{4}{c}{ Organic group ratio (mol\%) } & & $M_{\mathrm{w}}$ \\
\cline { 2 - 6 } & $(\mathrm{Ph})$ & (Mac) & (Suc) (Dime) & $M_{\mathrm{w}}$ & $M_{M_{\mathrm{n}}}$ \\
\hline Si-OLIGO-0 & 65 & 30 & 5 & - & 3000 & 1.7 \\
\hline Si-OLIGO-1 & 45 & 30 & 5 & 20 & 2820 & 1.7 \\
\hline
\end{tabular}

The results show that Si-OLIGO-0 and Si-OLIGO-1 had $M_{\mathrm{w}}$ of 3000 and 2820, respectively. This confirms that they are siloxane oligomers.

IR spectroscopy was used to confirm the structures having synthesized siloxane oligomers. IR spectra of prebaked films prepared from these solutions were recorded. First, we investigated the presence of absorption peaks near $900 \mathrm{~cm}^{-1}$ [22, 32], which are attributed to $\mathrm{Si}-\mathrm{OH}$ stretching. As shown in Fig. 4, signals near $900 \mathrm{~cm}^{-1}$ were observed in the spectra of Si-OLIGO-0 $\left(906 \mathrm{~cm}^{-1}\right)$ and Si-OLIGO-1 $\left(902 \mathrm{~cm}^{-1}\right)$.

However, it has been reported that almost no $\mathrm{Si}-\mathrm{OH}$ groups are present in SQs with highly regular cages and ladders [22, 23, 25-27]. The IR spectra therefore indicate that both of these siloxane oligomers have a random structure. Also, the $\mathrm{Si}-\mathrm{OH}$ signal in the $\mathrm{Si}-\mathrm{OLIGO}-1$ spectrum is similar to that in the Si-OLIGO-0 spectrum despite reducing trifunctional groups due to the introduction of bifunctional Dime groups.

Next, we investigated the absorption peaks near $1100 \mathrm{~cm}^{-1}$, which correspond to $\mathrm{Si}-\mathrm{O}-\mathrm{Si}$ stretching [10, 22-27, 32-37]. The Si-OLIGO-0 spectrum has a strong, broad absorption peak at $1134 \mathrm{~cm}^{-1}$, which corresponds to asymmetric ring stretching of $\mathrm{Si}-\mathrm{O}$. The Si-OLIGO-1 spectrum shows two strong signals, at 1134 and $1094 \mathrm{~cm}^{-1}$. It has been reported that for trifunctional SQs with highly regular structures, the cage structure gives one sharp peak near $1100 \mathrm{~cm}^{-1}[25,26]$, and the ladder structure gives two strong absorptions, at 1150 and $1050 \mathrm{~cm}^{-1}$, which correspond to asymmetric ring stretching and symmetric ring stretching, respectively $[10,22,24,27,34-36]$. The absorption peaks in the spectrum of the synthesized Si-OLIGO-0 differ significantly from those in the spectra of compounds with cage and ladder structures. This strongly suggests a random structure [23, 32, 33, 35, 37]. Si-OLIGO-1 has two strong absorption peaks separated by only $40 \mathrm{~cm}^{-1}$, which is significantly different from the separation in the case of the ladder structure $\left(100 \mathrm{~cm}^{-1}\right)$. This strongly suggests that this is also a random structure. It is assumed that the absorption peaks of the synthesized siloxane oligomers differ because the randomness of the Si-OLIGO-1 structure is greater. This is because the degree of crosslinking in Si-OLIGO-1 is lower than that in Si-OLIGO-0 because of the introduction of bifunctional Dime groups. This spectroscopic analysis of $\mathrm{Si}-\mathrm{OH}$ and $\mathrm{Si}-\mathrm{O}-\mathrm{Si}$ groups shows that the synthesized Si-OLIGO-1 and Si-OLIGO-0 both have random structures.

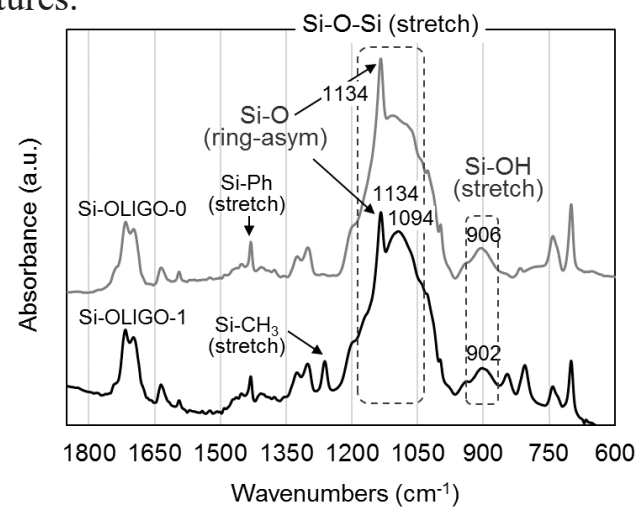

Fig. 4. IR spectra of prebaked films with Si-OLIGO-0 (gray line) and Si-OLIGO-1 (dark line). 
3.2. White decorative coating applications

\subsubsection{Properties of base resin}

The suitability of the synthesized Si-OLIGO-1 as a base resin for white decoration was investigated by comparing its performance with that of an acrylic polymer (SPCR-24X), which is expected to turn yellow because of oxidative degradation.

First, the transparency and heat resistance (determined from the $1 \%$ weight-loss temperature) were determined for $10 \mu \mathrm{m}$ thick cured films of PS-coatings (a) and (b), which contain no white pigment (Table 1).

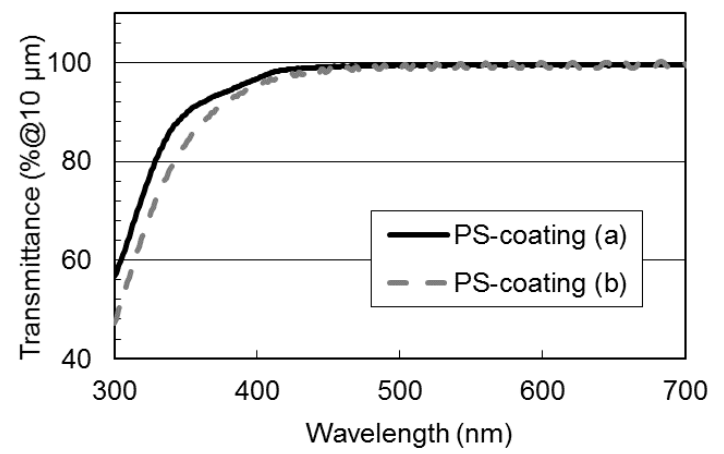

Fig. 5. Comparison of base resins from transmittances of cured films.

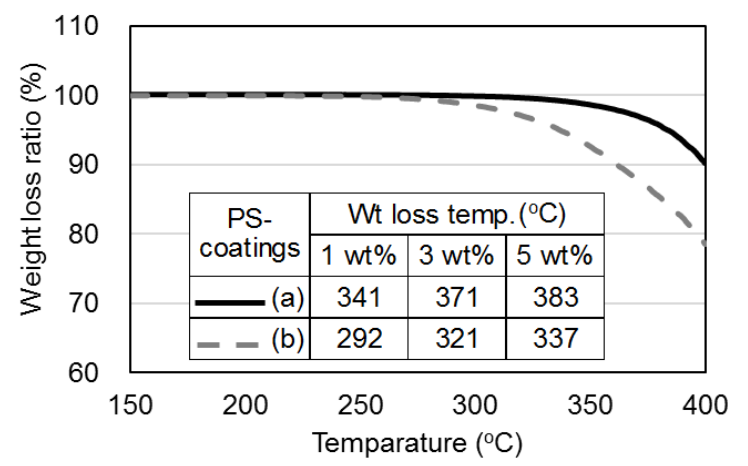

Fig. 6. Comparison of base resin heat resistances from weight-loss temperatures of cured films.

The results show that both PS-coatings have the same good transparency (Fig. 5). The 1\% weight-loss temperature of the PS-coating (a) is higher than that of the PS-coating (b) (Si-OLIGO-1, $341{ }^{\circ} \mathrm{C}$; SPCR-24X, $292{ }^{\circ} \mathrm{C}$ ). This shows that Si-OLIGO-1 has good heat resistance, as expected (Fig. 6). These results show that Si-OLIGO-1 is a suitable base resin for white decoration because the siloxane main chain is less susceptible to oxidative degradation.

\subsubsection{White cured film characteristics}

The abilities of the coatings to impart good white properties were investigated by determining the brightness $\left(L^{*}\right)$, color $\left(a^{*}, b^{*}\right)$, and reflectivity-wavelength dependences of films cured at $230{ }^{\circ} \mathrm{C}$ for $30 \mathrm{~min}$ with $10 \mu \mathrm{m}$-thick PS-coatings (c)-(f), which contain a white pigment. The results (Table 3) show that to satisfy the customer's requirements $\left(L^{*}>88 ;-3<a^{*}<1, b^{*}\right.$ $<1$; reflectivity $>75 \%$; Fig. 1 ), over $40 \mathrm{wt} \%$ of $250 \mathrm{~nm} \mathrm{TiO}_{2}$ pigment is needed, e.g., PS-coatings (e) and (f).

Table 3. Effects of $\mathrm{TiO}_{2}$ content and base resin on white cured film characteristics.

\begin{tabular}{ccccc}
\hline Thickness & \multicolumn{4}{c}{ PS-coatings } \\
\cline { 2 - 5 }$(10 \mu \mathrm{m})$ & (c) & $(\mathrm{d})$ & $(\mathrm{e})$ & $(\mathrm{f})$ \\
\hline $\mathrm{L}^{*}$ & 83.9 & 84.4 & 89.3 & 89.9 \\
$\mathrm{a}^{*}$ & -2.07 & -2.26 & -2.23 & -2.46 \\
$\mathrm{~b}^{*}$ & -2.38 & -1.32 & -0.96 & 1.57 \\
$\begin{array}{c}\text { Reflectivity (\%) } \\
\text { @550 nm }\end{array}$ & 63.9 & 62.8 & 75.8 & 75.3 \\
\hline
\end{tabular}

The $b^{*}$ values of PS-coatings (c) and (e) were smaller than those of PS-coatings (d) and (f) $(-2.38,-0.96$ and $-1.32,1.57$, respectively). The results show that the susceptibility of base resin Si-OLIGO-1 to oxidative degradation during curing at $230{ }^{\circ} \mathrm{C}$ is lower than that of the acrylic polymer SPCR-24X. The reflectivity-wavelength dependence (Fig. 7) shows that when $40 \mathrm{wt} \%$ of the $\mathrm{TiO}_{2}$ pigment was introduced, the reflectivity was over $75 \%$ in the visible-light region.

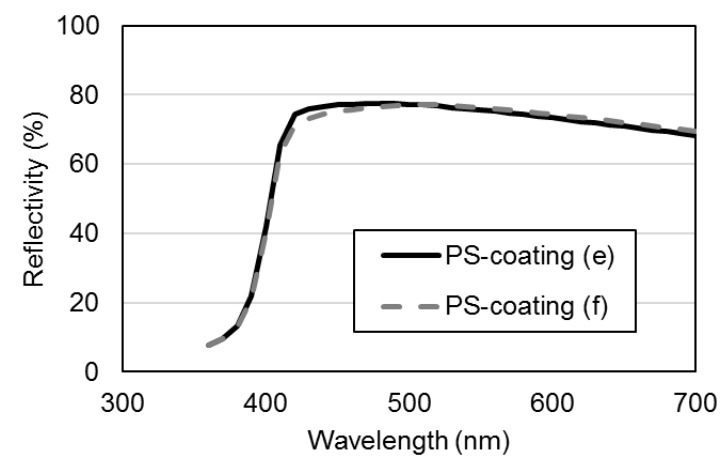

Fig. 7. Dependence of PS-coating (e) and (f) reflectivity on wavelength.

Next, the effect of heat treatment of PS-coatings (e) and (f) on the white film characteristics were investigated. A cured film was prepared by heating at $230{ }^{\circ} \mathrm{C}$ for $30 \mathrm{~min}$ and then heating at $250{ }^{\circ} \mathrm{C}$ for $30 \mathrm{~min}$. The $L^{*}, a^{*}$, and $b^{*}$ values of the cured film and the film that was further heated were determined. The results (Table 4) show that the PS-coating (e) has good white film characteristics 
because of the smaller change in $b^{*}$, which denotes yellowness, compared with that for the PS-coating (f) (1.7 and 3.62, respectively). It is presumed that this is also because the siloxane main chain is less susceptible to oxidative degradation.

Table 4. Comparison of white film characteristics after heat treatment.

\begin{tabular}{|c|c|c|c|c|}
\hline \multirow{2}{*}{$\begin{array}{l}\text { Thickness } \\
(10 \mu \mathrm{m})\end{array}$} & \multicolumn{2}{|c|}{ PS-coating (e) } & \multicolumn{2}{|c|}{ PS- coating (f) } \\
\hline & $\begin{array}{l}\text { no } \\
\text { treat. }\end{array}$ & $\begin{array}{l}250^{\circ} \mathrm{C} \\
130 \mathrm{~min}\end{array}(\Delta)$ & $\begin{array}{l}\text { no } \\
\text { treat. }\end{array}$ & $\begin{array}{l}250^{\circ} \mathrm{C} \\
130 \min \end{array}(\Delta)$ \\
\hline$L^{*}$ & 89.3 & $89(-0.3)$ & 89.9 & $89.1(-0.8)$ \\
\hline$a^{*}$ & -2.23 & $-2.52(-0.29)$ & -2.46 & $-2.48(-0.02)$ \\
\hline$b^{*}$ & -0.96 & $0.74(1.7)$ & 1.57 & $5.19(3.62)$ \\
\hline
\end{tabular}

The chemical resistance of a cured film of PS-coating (e) to various chemicals was investigated on various substrates. The results (Table 5) show that there were no visible changes to the film, e.g., peeling or color changes, and that the film had good white film characteristics.

Table 5. Chemical resistance of cured film derived from PS-coating (e).

\begin{tabular}{c|c|c|c}
\hline Chemicals & Condition & Substrate & Result \\
\hline \multirow{2}{*}{$\begin{array}{c}\text { TMAH } \\
(2.38 \text { wt } \%)\end{array}$} & \multirow{2}{*}{$23^{\circ} \mathrm{C} / 3 \mathrm{~min}$} & Glass & no change \\
\cline { 3 - 4 } & & $\mathrm{ITO}$ & no change \\
\cline { 3 - 4 } $\begin{array}{c}\text { Resist stripper } \\
\mathrm{N}-300^{*}\end{array}$ & \multirow{2}{*}{$45^{\circ} \mathrm{C} / 3 \mathrm{~min}$} & $\mathrm{Cr}$ & no change \\
\cline { 3 - 4 } & & $\mathrm{ITO}$ & no change \\
\cline { 3 - 4 } $\begin{array}{c}\text { Oxalic acid } \\
(0.05 \mathrm{~mol} / \mathrm{l})\end{array}$ & \multirow{3}{*}{$35^{\circ} \mathrm{C} / 3 \mathrm{~min}$} & $\mathrm{Glass}$ & no change \\
\cline { 3 - 4 } & & $\mathrm{ITO}$ & no change \\
\cline { 3 - 4 } & & $\mathrm{Cr}$ & no change \\
\hline
\end{tabular}

${ }^{*} \mathrm{~N}-300 ;$ MEA/DGBE $=30 / 70$ wt ratio.

These results show that PS-coating (e), with 40 $w t \%$ of $\mathrm{TiO}_{2}$ pigment introduced into Si-OLIGO-1 with a siloxane oligomer as the base resin, was suitable for use as a white decorative film.

\subsubsection{Patterning performance}

Before patterning the PS-coating (e), the straight transmittance of a prebaked film formed on a glass substrate $(11.7 \mu \mathrm{m})$ was determined in the wavelength range $300-700 \mathrm{~nm}$; this includes exposure to g-line (436 nm), h-line $(405 \mathrm{~nm})$, and i-line $(365 \mathrm{~nm})$ light. As shown in Fig. 8, no light was transmitted because of the effects of reflection and absorption by $\mathrm{TiO}_{2}$. Next, the scattering transmittance was determined in the same range. The results show that some of the g-line and h-line light was transmitted by scattered light. It is therefore assumed that the light reaches the bottom of the film and a pattern can be formed.

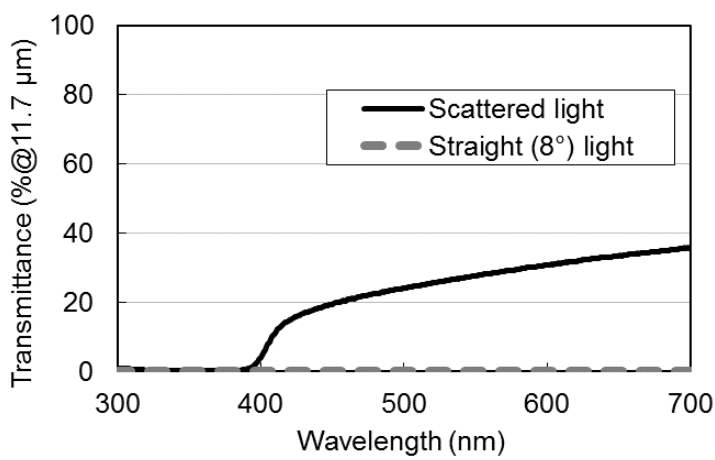

Fig. 8. Straight and scattered transmittances of cured film.

Patterning was performed using a mask and PS-coating (e). The results (Table 6) show a good resolution and pattern shape (taper angle), which satisfy customer requirements (resolution $<150$ $\mu \mathrm{m}$; taper angle $30^{\circ}-50^{\circ}$ ), at an exposure of $200-250 \mathrm{~mJ} / \mathrm{cm}^{2}$.

Table 6. Patterning performance of PS-coating (e).

\begin{tabular}{cccccc}
\hline & \multicolumn{5}{c}{ PS-coating (e) } \\
\cline { 2 - 6 } $\begin{array}{c}\text { Expo. dose } \\
\left(\mathrm{mJ} / \mathrm{cm}^{2}\right)\end{array}$ & 175 & 200 & 225 & 250 & 275 \\
\hline $\begin{array}{c}\text { Resolution } \\
(\mu \mathrm{m})\end{array}$ & 80 & 80 & 100 & 100 & 150 \\
$\begin{array}{c}\text { Taper } \\
\text { angle }\left(^{\circ}\right)\end{array}$ & 65 & 40 & 35 & 35 & 30 \\
\hline $\begin{array}{c}\text { SEM } \\
\text { image }\end{array}$ & & & & & \\
\hline
\end{tabular}

We successfully created a novel negative photosensitive white decorative siloxane coating, which contained a siloxane oligomer Si-OLIGO-1 as a base resin and $40 \mathrm{wt} \%$ of $\mathrm{TiO}_{2}$ (particle size $250 \mathrm{~nm}$ ) as the pigment. This coating can endow white film characteristics and ensure a good patterning performance.

\section{Conclusion}

A siloxane oligomer (Si-OLIGO-1) that can form a thick film was synthesized by introducing a bifunctional alkoxysilane into a SQ composed of a trifunctional alkoxysilane via a sol-gel method. IR spectroscopic analysis showed that Si-OLIGO-1 has a random structure with many acidic silanol groups capable of alkaline development. The transparency of a cured film formed from Si-OLIGO-1 was approximately the same, and the heat resistance was better, than those of an acrylic polymer. A white pigment was introduced into 
Si-OLIGO-1 to create a negative photosensitive white decorative coating. When $40 \mathrm{wt} \%$ of $\mathrm{TiO}_{2}$ (particle size $250 \mathrm{~nm}$ ) was introduced as the white pigment, a white cured film of thickness $10 \mu \mathrm{m}$ had the brightness $\left(L^{*}\right)$ and color $\left(a^{*}, b^{*}\right)$ required for white frames of display products. This coating also has potentially good chemical resistance when used in practical applications. This white decorative coating did not transmit straight light in the exposure light range required for negative pattern processing, but partly transmits scattered g-line and h-line light. This coating therefore gave the good resolution and pattern shape that were required by a customer at an exposure dose of $200-250 \mathrm{~mJ} / \mathrm{cm}^{2}$.

The novel negative photosensitive white decorative siloxane coatings created by this method have good film properties and give good patterning performances. They are suitable for complex white decorations, and modified formulations can be applied to devices such as smartphones and tablets.

\section{Acknowledgement}

We would like to thank the staff of the Electronic and Imaging Materials Research Laboratories, Toray Industries, Inc., for their cooperation in carrying out this research.

\section{References}

1. Japanese patent No. 6008436.

2. Japanese patent No. 6405004.

3. Japanese patent No. 5860419.

4. Japanese patent No. 6192556.

5. Japanese patent No. 6139894.

6. Japanese patent No. 6167805.

7. Japanese patent No. 5751929.

8. Japanese patent No. 6365118.

9. Japanese patent No. 6375236.

10. J. F. Brown Jr., L. H. Vogt Jr., A. Katchman, J. W. Eustance, K. M. Kiser, and K. W. Krantz, J. Am. Chem. Soc., 82 (1960) 6194.

11. J. F. Brown, L. H. Vogt, and P. I. Prescott, J. Am. Chem. Soc., 86 (1964) 1120.

12. M. Smaihi and T. Jermoumi, Chem. Mater., 7 (1995) 2293.

13. E. Lee and Y. Kimura, Polym. J., 30 (1998) 730.

14. J. J. Schwab and J. D. Lichtenhan, Appl. Organometal. Chem., 12 (1998) 707.

15. N. Takamura, T. Gunji, H. Hatano, and Y. Abe, J. Polym. Sci., Part A, Polym. Chem., 37 (1999) 1017.
16. F. J. Feher, R. Terroba, and J. W. Ziller, Chem. Commun. (1999) 2309.

17. N. Yasuda, S. Yamamoto, S. Minami, H. Nobutoki, Y. Wada, and S. Yanagida, Jpn. J. Appl. Phys., 41 (2002) 624.

18. R. Duchateau, Chem. Rev., 2 (2002) 3525.

19. M. Unno and H. Matsumoto, J. Organometal. Chem., 692 (2007) 307.

20. H. Seki, T. Kajiwara, Y. Abe, and T. Gunji., $J$. Org. Chem., 695 (2010) 1363.

21. J. J. Schwab and J. D. Lichtenhan, Appl. Organometal. Chem., 12 (1998) 707.

22. E. S. Park, H. W. Ro, C. V. Ngnyen, R. L. Jaff, and D. Y. Yoon, Chem. Matter, 20 (2008) 1548.

23. Z. X. Chang, J. Hao, P. Xie, X. Zhang, C. C. Han, and R. Zhang, Chem. Mater., 20 (2008) 1322.

24. M. Handke, B. Handke, A. Kowalewska, and W. Jastrzebski, J. Mol. Struct., 924 (2009) 254.

25. M. Dutkiewicz, M. Szołyga, H. Maciejewski, and B. Marciniec, J. Therm. Anal. Calorim., 117 (2014) 259.

26. M. M. Rahman, V. Filiz, M. M. Khan, B. N. Gacal, and V. Abetz, Reac. Funct. Polym., 86 (2015) 125.

27. Y. Tashiro, A. Miyazato, and K. Ebitani, J. Inorg. Organomet. Polym., 25 (2015) 1353.

28. T. Okazawa, K. Ono, and M. Suwa, J. Photopolym. Sci. Technol., 25 (2012) 349.

29. Y. Nakahara, H. Kawa, J. Yoshiki, M. Kumei, H. Yamamoto, F. Oi, H. Yamakado, H. Fukuda, and K. Kimur, Thin Solid Films 520 (2012) 7195.

30. J. A. Tossell and N. Sahai, Geochim. Cosmochim. Acta, 64 (2000) 4097.

31. M. M. Fickling, A. Fischer, B. R. Mann, J. Packer, and J. Vaughan, J. Am. Chem. Soc., 81 (1959) 4226.

32. N. Takano, T. Fukuda, and K. Ono, Kobunshi Ronbunshu, 57 (2000) 743 (in Japanese).

33. Y. Tashiro, T. Sekito, T. Iwata, D. Yokoyama, and T. Nonaka, Proc. SPIE, 7140 (2008) $71402 \mathrm{O}$.

34. Y. Kaneko and N. Iyi, Kobunshi Ronbunshu, 67 (2010) 280 (in Japanese).

35. A. Kolezynski, W. Tastrzebski, and W. Sitarz, J. Mol. Struct., 1044 (2013) 314.

36. W. Szczypka, K. Jelen, and K. Andrzej, J. Mol. Struct., 75 (2014) 599.

37. Y. Tashiro, A. Miyazato, and K. Ebitani, J. Photopolym. Sci. Technol., 28 (2015) 239. 